\title{
Resource utilization after thoracic aortic aneurysm repair: An examination of the endovascular approach in the United States
}

\author{
Alexander Iribarne ${ }^{3}$, Ashwin Karanam ${ }^{1,2}$, Dhaval Chauhan ${ }^{1,2}$, Aurelie Merlo ${ }^{4}$, Noah Bressner ${ }^{2}$, Ross Milner and Mark J Russo $^{1,2}$ \\ ${ }^{1}$ Department of Surgery, New Jersey Medical School - Rutgers, Newark, NJ, USA \\ ${ }^{2}$ Cardiovascular Clinical Research Unit, Barnabas Heart Hospitals, NJ, USA \\ ${ }^{3}$ Department of Cardiothoracic Surgery, Dartmouth Medical Center, Hanover, NH, USA \\ ${ }^{4}$ Case Western Medical School, Cleveland, OH, USA \\ ${ }^{5}$ Section of Vascular Surgery, Division of Surgery, University of Chicago, Chicago, IL, USA
}

\begin{abstract}
Purpose: To examine the resource utilization of the endovascular approach for thoracic aortic aneurysm (TAA) repair, and quantify the incremental effect of complications on hospital costs and length of stay (LOS).

Methods: De-identified patient-level claims data on a random sample of TAA repairs performed in the US from January 1st, 2008 to December 31 st, 2008 were obtained from the Nationwide Inpatient Sample ( $\mathrm{n}=3,794)$. Risk-adjusted total hospital costs and LOS were analyzed by major complication.

Results: Analysis included 989 (26.1\%) people undergoing Thoracic Endovascular Aneurysm Repair (TEVAR). The median LOS was 6 days and the median cost was $\$ 46,059$. There was a stepwise increase in resource utilization as function of the number of complications per patient $(\mathrm{p}<0.001)$; among TEVAR the most resource intensive complications on a per patient basis were myocardial infarction and venous thromboembolism.

Conclusion: TEVAR patients continue to show improvements in LOS and resource utilization. However, post-operative complications resulted in compounded hospital costs and increased length of stay. Quality improvement efforts reducing the risk of these post-operative complications have the potential to provide significant cost savings.
\end{abstract}

\section{Introduction}

Outcome related to the management of thoracic aortic aneurysms (TAA) has undergone a paradigm shift over the past decade $[1,2]$. While open TAA repair for TAA remains the standard, it is still associated with mortality rates in some series as high as $50 \%$ as well as significant rates of paraplegia and renal failure [3-5] in 2005 Food and Drug Administration approved thoracic endovascular aortic repair (TEVAR), for treatment of TAA [6,7].

Several recent studies have demonstrated that this less invasive approach is associated with decreased rates of mortality and major complications [8-10]. For example, in a large national series of patients undergoing TEVAR and open TAA repair, the TEVAR approach was associated with $60 \%$ fewer complications overall, and a shorter hospital length of stay [8]. In addition, superior midterm survival with TEVAR has been observed at 1, 3, and 5 years when compared to the open approach [10].

While endografts themselves are associated with shorter duration of hospitalization, decreased incidence of post-operative complications, and faster rehabilitation, postoperative complication remain common. However, detailed data regarding the clinical and economic impact of postoperative complications, particularly after TEVAR, remain scarce. Availability of this information could be used to target further quality improvement efforts, which may significantly improve outcomes for patients and cost containment efforts in an era when cost effectiveness is at the forefront of healthcare policy initiatives.

The purpose of this study was to characterize the impact of postoperative complications on clinical outcomes, such as mortality and discharge disposition, and the net increase in resource utilization including in-hospital cost and length of stay, in a national cohort of patients undergoing TEVAR for TAA.

\section{Materials and methods}

\section{Data source}

The Nationwide Inpatient Sample (NIS), which is sponsored by the Agency for Healthcare Research and Quality, Healthcare Cost and Utilization Project (HCUP), was used to identify patient discharges related to TAA repairs that occurred from January 1,2008 - December 31,2008 . The study period was chosen to allow for adequate time for

Correspondence to: Dhaval Chauhan, Newark Beth Israel Medical Center, Barnabas Health Heart Centers, 201 Lyons Ave, Suite G5, Newark, NJ 07112, Phone: 973-926-6938, Fax: 973-923-4683; E-mail: dhavalchauhan86@gmail.com

Key words: resource utilization, aortic aneurysm, thoracic endovascular aortic repair, TEVAR

Received: June 28, 2016; Accepted: June 13, 2016; Published: June 16, 2016 
data auditing. The NIS provides only de-identified patient claims data and thus this analysis qualified for institutional IRB exception. The NIS is a $20 \%$ sampling of abstracted discharge data from a national survey of all non-federal acute-care hospitals in the United States and contains discharge records from over 1,000 hospitals [11].

The NIS contains up to 15 procedure codes per patient using the International Classification of Diseases, Ninth Revision, Clinical Modification (ICD-9-CM) procedure code index. Data on TAA surgery was abstracted using ICD-9-CM codes diagnostic (441.2) and procedural $(38.45,39.73)$ in either the first, second, or third procedure code position. Only patients undergoing isolated aortic surgery who were $\geq 18$ years-old were included in the analysis for a sample size of 3,794 patients. The NIS does not provide data on repeat procedures or mortality beyond the index hospital admission.

\section{Clinical outcomes}

Clinical outcomes of interest included in-hospital death, length of hospital stay, post-operative morbidity measures including number of complications per patient and their discharge disposition. NIS dataset on an average reports 15 diagnoses for a discharge. In order to focus on specific complications, we concentrated on specific complications in post-operative period e.g. pneumonia rather than system based categories of complications e.g. respiratory complications. Following major complications in post-operative period using appropriate ICD9 codes were included in analysis: Sepsis, renal failure, myocardial infarction (MI), pneumonia, venous thromboembolism (VTE) and stroke.

\section{Cost outcomes}

Total billed charges for each hospitalization are present in the NIS dataset. These data reflect the amount hospitals billed for services rendered rather than the costs for the specific hospitalization or the amount hospitals received in payments. Estimated institutional cost data was obtained by multiplying HCUP supplied cost-to-charge ratios by total charges. Grouped average cost-to-charge ratios are a weighted average for the hospitals in the group (defined by state, urban/rural, investor owned/other, and number of beds) and use the proportion of group beds as the weight for each hospital. In this analysis, the major cost endpoint was the median cost of the index hospitalization. All costs were rounded to the nearest $\$ 1,000$.

\section{Statistical analysis}

For clinical data, continuous variables were reported as mean \pm standard error. Categorical variables were reported as percentages. Both mean and median lengths of stay are reported, however, median length of stay was used as the primary outcome measure when assessing the incremental effect of complications given the potential for outliers. To quantify the incremental effect of complication type on median length of stay, multivariable quantile regression with 1,000 bootstrapped iterations was employed using the all-patient-refined diagnosis related group (APR-DRG) classification as a covariate for risk-adjustment [12-14]. Similarly for cost data, mean and median are reported, however, median cost was used as the primary outcome measure when assessing the incremental effect of complication type on median cost since medical costs are traditionally right skewed. Multivariable quantile regression with 1,000 bootstrapped iterations using APR-DRG for risk adjustment was also employed in the analysis of the effect of complication type on incremental median cost. For all analyses, the conventional p-value of 0.05 or less was used to determine the level of statistical significance. All reported p-values are two-sided.
All statistical analyses were performed using Stata 11 (Stata Corp, College Station, TX).

\section{Results}

\section{Study population}

From January 1, 2008 to December 31, 2008, a total of 3,794 patients in the NIS registry underwent a thoracic aortic aneurysm repair. Of these cases, $26.1 \%$ ( $n=989)$ were performed via endovascular approach. The distribution of baseline characteristics for the study cohort is summarized in Table 1. Overall, the three most common comorbidities included: hypertension $(69.6 \%, \mathrm{n}=688)$, peripheral vascular disease $(36.5 \%, \mathrm{n}=361)$, and chronic lung disease $(29.3 \%, \mathrm{n}=290)$.

\section{Clinical outcomes}

Overall mortality for the study cohort was $6.0 \%(n=59)$. The unadjusted mean LOS for TEVAR was $10.4 \pm 0.5$ days. When riskadjusted by APR-DRG, the TEVAR approach was associated with a median LOS, of 6 days. The distribution of post-operative complications for the series is summarized in Table 2. Overall there were a total of 369 complication events which occurred in 299 patients. The three most common complications were: renal failure $(11 \%, \mathrm{n}=109)$, septicemia $(9.7 \%, \mathrm{n}=96)$, and pneumonia $(8.3 \%, \mathrm{n}=82)$.

Table 1. Baseline characteristics of study cohort.

\begin{tabular}{|l|c|}
\hline Age & $\begin{array}{c}\text { TEVAR } \\
(\mathrm{n}=989)\end{array}$ \\
\hline Gender $(\%$ male $)$ & $66 \pm 16$ \\
\hline Congestive heart failure & $61.9 \%(\mathrm{n}=612)$ \\
\hline Chronic lung disease & $1.4 \%(\mathrm{n}=14)$ \\
\hline Coagulopathy & $29.3 \%(\mathrm{n}=290)$ \\
\hline Diabetes & $9.2 \%(\mathrm{n}=91)$ \\
\hline Hypertension & $14.2 \%(\mathrm{n}=140)$ \\
\hline Chronic liver disease & $69.6 \%(\mathrm{n}=688)$ \\
\hline Neurological disorders & $1.0 \%(\mathrm{n}=10)$ \\
\hline Obesity & $3.4 \%(\mathrm{n}=34)$ \\
\hline Peripheral vascular disease & $7.2 \%(\mathrm{n}=71)$ \\
\hline Renal failure & $36.5 \%(\mathrm{n}=361)$ \\
\hline Valvular heart disease & $12.5 \%(\mathrm{n}=124)$ \\
\hline & $0.3 \%(\mathrm{n}=3)$ \\
\hline
\end{tabular}

Table 2. Distribution of post-operative complications and number of complications per patient.

\begin{tabular}{|c|c|}
\hline & TEVAR \\
$(\mathrm{n}=989)$
\end{tabular}




\section{Resource utilization}

The subjects had an unadjusted mean hospitalization cost of $\$ 63,121 \pm \$ 1,916$ and a median cost of $\$ 46,059$. The majority of subjects developed no complications $(69.8 \%, \mathrm{n}=690)$, with nearly a quarter of subjects experiencing one complication event $(24.6 \%, \mathrm{n}=243)$. The risk-adjusted net increase in median hospital costs and LOS stratified by complication type is shown in Table 3. Among TEVAR patients, MI accounted for the greatest net increase in hospital costs $(\$ 72,328$ $\pm \$ 9,138 ; \mathrm{p}<0.001)$ and VTE accounted for the greatest net increase in $\operatorname{LOS}(17.0 \pm 3.1$ days; $\mathrm{p}<0.001)$.

There was a stepwise association between the number of complications per patient and both hospital costs and LOS $(\mathrm{p}<0.001)$. With one complication, hospital cost and LOS increased by $\$ 20,352$ and 5 days, respectively, for TEVAR patients. Hospital costs and LOS rose progressively from one to two complications, did not change significantly from two to three complications, and then increased significantly beyond three complications.

In terms of discharge disposition, $54.4 \%$ of TEVAR patients had a routine home discharge, $17.8 \%$ were discharged to a skilled nursing facility, and $18.1 \%$ were discharged home with the assistance of a health aide.

\section{Discussion}

This analysis describes the influence of complications on resource utilization among a large national cohort of patients undergoing TAA repair using TEVAR. Based on the results of this analysis, complications had a significant impact on both cost and length of stay for TEVAR patients.

Table 3. Incremental median net increase in hospital cost and length of stay by complication category for TEVAR patients.

\begin{tabular}{|l|c|c|c|c|}
\hline $\begin{array}{l}\text { Complication } \\
\text { Category }\end{array}$ & $\begin{array}{l}\text { Median net increase } \\
\text { in hospital costs (\$) }\end{array}$ & p-value & $\begin{array}{c}\text { Median net } \\
\text { increase in } \\
\text { LOS (days) }\end{array}$ & p-value \\
\hline Pneumonia & $38.415 \pm 4.357$ & $<0.001$ & $9.0 \pm 0.9$ & $<0.001$ \\
\hline Septicemia & $4.122 \pm 4.278$ & 0.335 & $0.14 \pm 0.9$ & 0.875 \\
\hline Renal failure & $34.020 \pm 3.705$ & $<0.001$ & $5.0 \pm 0.8$ & $<0.001$ \\
\hline Myocardial infarction & $72.328 \pm 9.138$ & $<0.001$ & $8.0 \pm 2.2$ & $<0.001$ \\
\hline Stroke & $36.062 \pm 4.747$ & $<0.001$ & $6.0 \pm 0.7$ & $<0.001$ \\
\hline $\begin{array}{l}\text { Venous } \\
\text { thromboembolism }\end{array}$ & $52.337 \pm 13.117$ & $<0.001$ & $17.0 \pm 3.1$ & $<0.001$ \\
\hline
\end{tabular}

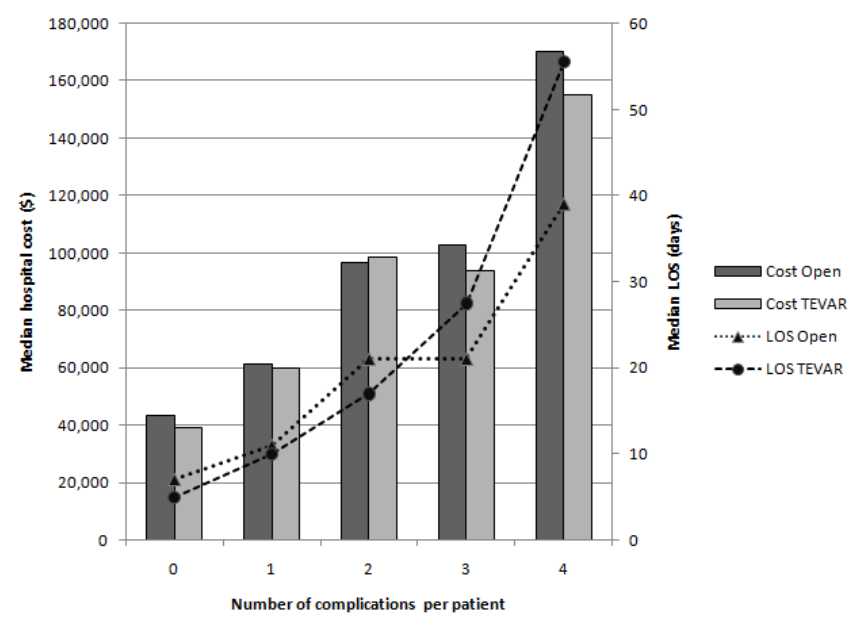

Figure 1. Graph showing number of complications per patient.

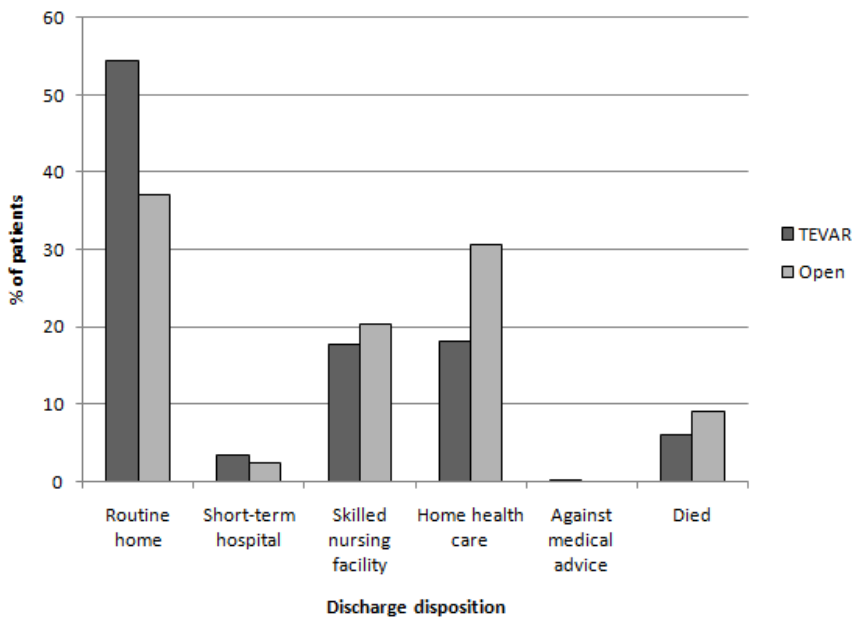

Figure 2. Graph showing \% of patients $v s$. discharge disposition.

Since TEVAR first received FDA approval in 2005, several retrospective analyses have attempted to further clarify the comparative effectiveness of open versus endovascular approaches for TAAs [1517]. The majority of these analyses have demonstrated either equivalent or improved results with the endovascular approach. For example, an early study by Orandi and colleagues conducted on national data from the last three months in 2005, demonstrated no significant difference in mortality between groups and fewer cardiac, respiratory, and hemorrhagic complications among TEVAR patients [18]. Further analyses by Sachs and colleagues demonstrated that despite being performed on older patients with greater co-morbidities, the TEVAR approach was associated with reduced in-hospital mortality and morbidity [9].

In our analysis, which focuses on a large national cohort of patients, we demonstrate that outcomes in LOS and complications have continued to improve for TEVAR patients. Despite the elevated mean age of our cohort (66 years), and the presence of significant comorbidities (e.g. renal failure, sepsis, and pneumonia), patients had a relatively low length of stay (10.4 \pm .5 days) and low in-hospital costs $(\$ 63,121 \pm \$ 1,916)$. A recent analysis by Bhamidipati and colleagues showed that since 2005 there has been a steady risk-adjusted annual decrease in mortality with TEVAR on a national level [6]. Thus, as with many innovative technologies, experience over time, as it relates to both patient selection and technical skills, may account for the improved outcomes observed with TEVAR in this contemporary analysis.

The ability to recognize that the cost effectiveness of new technology will often improve with experience and reductions in device cost is essential in the planning of comparative effectiveness trials for innovative devices [19]. Notably, the rate of home discharge was $54.4 \%$, demonstrating that if the time horizon of the analysis was extended beyond the index hospitalization, further cost savings of the endovascular approach may be observed.

The Centers for Medicare and Medicaid Services (CMS) of the United States issued Hospital Inpatient Value-Based Purchasing Program final rule in 2011. According to the rule, hospitals performing well on certain quality measures related to patient experience as well as clinical process will be provided with higher payments compared to their counterparts. This initiative was intended to reward hospitals for their provision of better quality of care and reduce health care costs [20]. The rule was applied on October 1, 2012 and defined major change 
in payer strategies by government of the United States highlighting importance of understanding process of care and making necessary improvements.

Despite the potential improvements in cost effectiveness observed with TEVAR, it is important to note that complication rates after TEVAR remained relatively high compared to other cardiac surgical procedures, and are a persistent source of significant resource utilization regardless of the type of approach. Compared to patients with no complications, those experiencing only one complication had a median increase in hospital costs of approximately $\$ 20,000$, and an additional $\$ 30,000$ for two complications. Thus, quality improvement initiatives and measures focused on perioperative management goals to reduce complications have a significant cost saving potential. In contemporary practice where there is rising pressure to improve clinical outcomes along with a drive for containment of costs, quality measures will heavily influence financial reimbursement in healthcare services $[20,21]$. Our study demonstrates possible areas where quality improvement initiatives may be focused.

Several quality improvement initiatives aimed at reducing pneumonia through bundling strategies for intubated patients have shown improvements in outcomes and hospital costs which may be incorporated in cardiothoracic intensive care units [22,23]. Renal failure was the most common complication among TEVAR patients and MI and VTE were responsible for the greatest net increase in costs $(\$ 72,328)$ and length of stay (17 days), respectively. Thus, our analysis demonstrates that quality improvement initiatives need to be designed to address these specific complications. These may include preventive measures, more aggressive preoperative screening for the condition, or changing patient selection.

\section{Limitations}

There are several limitations to our analysis. First, the NIS is an administrative database and does not contain detailed clinical information on a variety of measures, such as anatomy of the aneurysm or baseline laboratory values. Second, only $20 \%$ of nationwide institutions are sampled within the NIS; therefore, there exists the potential for variability in an individual center's annual aortic surgery volumes. Third, follow-up did not extend beyond the index hospitalization; consequently, important events, such as followup imaging, or complications that may have occurred after discharge were not captured. Fourth, the use of ICD-9 codes to identify clinical events is imperfect, and as with all administrative registries subject to reporting bias and potential coding errors. Nevertheless, many of the limitations in this analysis must be understood in the context of the strengths of the NIS, which include its large size, representative quality, and standardized methodology of survey.

\section{Conclusion}

Overall mortality of this cohort was $6 \%$. Median LOS was 6 days, and median in-hospital cost was $\$ 46,059$. The most resource intense complications on a per patient basis were myocardial infarction and venous thromboembolism. Increasing number of complications per patients resulted in a disproportionally increased cost and a stepwise increase in resource utilization. In times where attention to improving quality and containing cost is increasing, understanding the impact of complications on costs and outcomes is of paramount importance. This analysis may help drive quality improvement initiatives as well as improve cost-effectiveness and ultimately improve patient outcomes.

\section{Acknowledgement}

All the authors contributing to the manuscript have been included in author string.

\section{References}

1. Andritsos M, Desai ND, Grewal A, Augoustides JGT (2010) Innovations in aortic disease management: the descending aorta. J Cardiothorac Vasc Anesth 24: 523-529. [Crossref]

2. Fischbein MP, Miller DC (2009) Long-term durability of open thoracic and thoracoabdominal aneurysm repair. Semin Vasc Surg 22: 74-80. [Crossref]

3. Bozinovski J, Coselli JS (2008) Outcomes and survival in surgical treatment of descending thoracic aorta with acute dissection. Ann Thorac Surg 85: 965-970 [Crossref]

4. Trimarchi S, Nienaber CA, Rampoldi V, Myrmel T, Suzuki T, et al. (2006) Role and results of surgery in acute type B aortic dissection: insights from the International Registry of Acute Aortic Dissection (IRAD). Circulation 114: I357-64. [Crossref]

5. Miller DC, Stinson EB, Oyer PE, Rossiter SJ, Reitz BA, Griepp RB, et al. Operative treatment of aortic dissections. Experience with 125 patients over a sixteen-year period. $J$ Thorac Cardiovasc Surg 78: 365-382. [Crossref]

6. Bhamidipati CM, LaPar DJ, Mehta GS, Kern JA, Kron IL, et al. (2011) Have thoracic endografting outcomes improved since US Food and Drug Administration approval? Ann Thorac Surg 91: 1314-1322 [Crossref]

7. Walker KL, Shuster JJ, Martin TD, Hess PJ, Klodell CT, Feezor RJ, et al. (2010) Practice patterns for thoracic aneurysms in the stent graft era: health care system implications. Ann Thorac Surg 90: 1833-1839. [Crossref]

8. Gopaldas RR, Huh J, Dao TK, LeMaire SA, Chu D, Bakaeen FG, et al. (2010) Superio nationwide outcomes of endovascular versus open repair for isolated descending thoracic aortic aneurysm in 11,669 patients. J Thorac Cardiovasc Surg 140: 10011010. [Crossref]

9. Sachs T, Pomposelli F, Hagberg R, Hamdan A, Wyers M, et al. (2010) Open and endovascular repair of type B aortic dissection in the Nationwide Inpatient Sample. Journal of vascular surgery 52: 860-6 [Crossref]

10. Zeeshan A, Woo EY, Bavaria JE, Fairman RM, Desai ND, Pochettino A, et al. (2010) Thoracic endovascular aortic repair for acute complicated type B aortic dissection: superiority relative to conventional open surgical and medical therapy. $J$ Thorac Cardiovasc Surg 140: S109-115

11. Rockville M (2001) Inpatient Sample (NIS). Healthcare Cost and Utilization Project (HCUP) Agency for Healthcare Research and Quality [Crossref]

12. Baram D, Daroowalla F, Garcia R, Zhang G, Chen JJ, et al. (2008) Use of the All Patient Refined-Diagnosis Related Group (APR-DRG) Risk of Mortality Score as a Severity Adjustor in the Medical ICU. Clinical medicine. Circulatory, respiratory and pulmonary medicine 2: 19-25. [Crossref]

13. Romano PS, Chan BK (2000) Risk-adjusting acute myocardial infarction mortality: are APR-DRGs the right tool? Health Serv Res 34: 1469-1489. [Crossref]

14. Avrill R, Goldfield N, Hughes J, Wallingford C (2003) All Patient Refined Diagnosis Related Groups (APR DRGs) Version 20. Methodology Overview 3 Information Systems. [Crossref]

15. Cheng D, Martin J, Shennib H, Dunning J, Muneretto C, et al. (2010) Endovascular aortic repair versus open surgical repair for descending thoracic aortic disease a systematic review and meta-analysis of comparative studies. J Am Coll Cardiol 55: 986-1001. [Crossref]

16. Xenos ES, Minion DJ, Davenport DL, Hamdallah O, Abedi NN, et al. (2009) Endovascular versus open repair for descending thoracic aortic rupture: institutional experience and meta-analysis. Eur J Cardiothorac Surg 35: 282-286. [Crossref]

17. Walsh SR, Tang TY, Sadat U, Naik J, Gaunt ME, Boyle JR, et al. (2008) Endovascular stenting versus open surgery for thoracic aortic disease: systematic review and metaanalysis of perioperative results. Journal of vascular surgery 47: 1094-1098. [Crossref]

18. Orandi BJ, Dimick JB, Deeb GM, Patel HJ, Upchurch GR (2009) A population-based analysis of endovascular versus open thoracic aortic aneurysm repair. Journal of vascular surgery 45: 1112-1116. [Crossref]

19. Iribarne A, Russo MJ, Moskowitz AJ, Ascheim DD, Brown LD, et al. (2009) Assessing technological change in cardiothoracic surgery. Semin Thorac Cardiovasc Surg 21 28-34. [Crossref] 
Iribarne A (2016) Resource utilization after thoracic aortic aneurysm repair: An examination of the endovascular approach in the United States

20. Chassin MR, Galvin RW (1998) The urgent need to improve health care quality. Institute of Medicine National Roundtable on Health Care Quality. JAMA 280: 10001005. [Crossref]

21. Institute of Medicine (2001) Crossing the quality chasm: a new health system for the twenty-first century. Washington, DC: National Academy Press
22. Morris AC, Hay AW, Swann DG, Everingham K, McCulloch C, et al. (2011) Reducing ventilator-associated pneumonia in intensive care: impact of implementing a care bundle. Crit Care Med 39: 2218-2224. [Crossref]

23. Marrie TJ, Lau CY, Wheeler SL, Wong CJ, Vandervoort MK, et al. (2000) A controlled trial of a critical pathway for treatment of community-acquired pneumonia. CAPITAL Study Investigators. Community-Acquired Pneumonia Intervention Trial Assessing Levofloxacin. JAMA 283: 749-755.

Copyright: (C2016 Iribarne A. This is an open-access article distributed under the terms of the Creative Commons Attribution License, which permits unrestricted use, distribution, and reproduction in any medium, provided the original author and source are credited. 